This document is the accepted manuscript version of the following article:

Yang, P., van der To1, C., Verhoef, w., Damm, A., Schickling, A., Kraska, T., ... Rascher, U. (2018). Using reflectance to explain vegetation biochemical and structural effects on suninduced chlorophy11 fluorescence. Remote Sensing of Environment, 231, 110996 (11 pp.). https:// doi.org/10.1016/j.rse.2018.11.039

This manuscript version is made available under the CC-BY-NC-ND 4.0 1icense http:// creativecommons.org/1icenses/by-nc-nd/4.0/

\title{
Using reflectance to explain vegetation biochemical and structural effects on sun-induced chlorophyll fluorescence
}

Peiqi Yang ${ }^{\mathrm{a}, *}$, Christiaan van der Tol ${ }^{\mathrm{a}}$, Wout Verhoef ${ }^{\mathrm{a}}$, Alexander Damm ${ }^{\mathrm{b}, \mathrm{c}}$, Anke Schickling ${ }^{\mathrm{d}}$, Thorsten Kraska ${ }^{\mathrm{e}}$, Onno Muller ${ }^{\mathrm{d}}$, Uwe Rascher ${ }^{\mathrm{d}}$

${ }^{a}$ Faculty of Geo-Information Science and Earth Observation (ITC), University of Twente, 7500 AE Enschede, The Netherlands

${ }^{b}$ Remote Sensing Laboratories, University of Zurich, Winterthurerstrasse 190, Zurich 8057, Switzerland

${ }^{c}$ Eawag, Swiss Federal Institute of Aquatic Science and Technology. Überlandstrasse 133, Dübendorf, Switzerland

${ }^{d}$ Institute of Bio- and Geosciences, IBG-2: Plant Sciences, Forschungszentrum Jülich GmbH, Leo-Brandt-Str., 52425 Jülich, Germany

${ }^{e}$ Field Lab Campus Klein-Altendorf, Agricultural Faculty, University of Bonn, Klein-Altendorf 2, 53359 Rheinbach, Germany

\begin{abstract}
The growing availability of global measurements of sun-induced chlorophyll fluorescence (SIF) can help in improving crop monitoring, especially the monitoring of photosynthetic activity. However, variations in top-of-canopy (TOC) SIF cannot be directly interpreted as physiological changes because of the confounding effects of vegetation biochemistry (i.e. pigments, dry matter and water) and structure. In this study, we propose an approach of using radiative transfer models (RTMs) and TOC reflectance to estimate the biochemical and structural effects on TOC SIF, as a necessary step in retrieving physiological information from TOC SIF. The approach was assessed by using airborne (HyPlant) reflectance and SIF data acquired over
\end{abstract}

\footnotetext{
${ }^{*}$ Corresponding author

Email address: p.yang@utwente.nl (Peiqi Yang)
} 
an agricultural experimental farm in Germany on two days, before and during a heat event in summer 2015 with maximum temperatures of $27^{\circ} \mathrm{C}$ and $34^{\circ} \mathrm{C}$, respectively. The results show that over $76 \%$ variation among different crops in SIF observations was explained by variation in vegetation biochemistry and structure. In addition, the changes of vegetation biochemistry and structure explained as much as $73 \%$ variation between the two days in farred SIF, and $40 \%$ variation in red SIF. The remaining unexplained variation was mostly attributed to the variability in physiological status. We conclude that reflectance provides valuable information to account for biochemical and structural effects on SIF and to advance analysis of SIF observations. The combination of RTMs, reflectance and SIF opens new pathways to detect vegetation biochemical, structural and physiological changes.

Keywords: chlorophyll fluorescence, reflectance, radiative transfer models, canopy structure, HyPlant, airborne

\section{Introduction}

Sun-induced chlorophyll fluorescence (SIF) has been effectively used as 3 a signal for monitoring vegetation physiology, because of its functional con4 nection to photosynthesis. The physiological mechanisms that regulate the 5 fluorescence emission by photosystems also affect the SIF signals measured by remote sensing techniques (Rascher et al., 2015). This is the basis for using SIF as an indicator of plant physiological status and stress (Ač et al., 2015;

8 Rossini et al., 2015). SIF is also an indicator of gross primary production 9 (GPP) as it contains information on both absorption of photosynthetically 10 active radiation (PAR) and energy partitioning in photosystems (Guanter 
et al., 2014; Yang et al., 2015; Migliavacca et al., 2017; Sun et al., 2017).

Besides physiological regulation, vegetation biochemical composition and structure also strongly affect SIF observations. Top-of-canopy (TOC) SIF is an outcome of three processes: absorption of incident PAR by chlorophylls (Zhang et al., 2018), emission of fluorescence by photosystems (Van der Tol et al., 2014), and scattering and re-absorption of emitted fluorescence (Yang and Van der Tol, 2018). The SIF emission depends on physiological mechanisms, which regulate the partitioning of PAR absorbed by chlorophylls $\left(\mathrm{APAR}_{c h l}\right)$ into three different de-excitation pathways: heat dissipation, photochemistry and fluorescence (Maxwell and Johnson, 2000; Baker, 2008). The incident PAR absorption and SIF scattering, however, are mainly determined by non-physiological factors, including vegetation biochemistry (e.g., leaf pigments, water and dry matter), structure, illumination angles (Grace et al., 2007; Porcar Castell et al., 2014) and observation angles (Liu et al., 2016; Köhler et al., 2018).

Consequently, variations in TOC SIF can not be directly interpreted as changes in plant physiological status. Studies have shown that a substantial portion of SIF variation at different spatial and temporal scales is due to vegetation biochemistry and structure rather than changes in energy partitioning in photosystems (Van der Tol et al., 2016; Migliavacca et al., 2017). A part of observed variation in TOC SIF is also caused by the different viewing angles (Liu et al., 2016; Köhler et al., 2018). Both canopy structure, leaf biochemistry and observational conditions largely affect the observed linear relationship between SIF and GPP (Migliavacca et al., 2017; Yang et al., 2018). Therefore, it is essential to first account for the non-physiological 
effects, before plant physiological changes can be inferred from TOC SIF.

Several simple approaches have been applied to account for variation in PAR absorption and fluorescence scattering (and re-absorption). The variation in PAR absorption of a canopy caused by different illumination conditions can be effectively corrected by normalizing SIF by incident PAR (Daumard et al., 2012). Normalizing SIF by $\mathrm{APAR}_{c h l}$ further takes variation in light absorption caused by different vegetation biochemistry and structure into account (Miao et al., 2018). Viewing angles have no impact on the light absorption process, but strongly affect the scattering of SIF into the viewing direction. The variation of SIF scattering caused by different viewing angles can be partly removed by angular normalization of SIF. He et al. (2017) demonstrated that the normalization improves the SIF-GPP correlation. However, these methods are not always sufficient to retrieve plant physiological status. First, $\mathrm{APAR}_{c h l}$ measurements are not always available. Second, the scattering and re-absorption of SIF vary significantly with canopy structure and leaf properties (e.g., leaf area index (LAI) and chlorophyll content) apart from viewing angles (Yang and Van der Tol, 2018). More general and explicit approaches to separate non-physiological (e.g., the vegetation biochemical, structural and observational condition) and physiological effects are required.

Vegetation radiative transfer models (RTMs) have been successfully used to evaluate the effects of vegetation biochemistry and structure on TOC SIF. RTMs offer an explicit connection between TOC SIF observations and vegetation biochemical and structural parameters, by modelling the light absorption and fluorescence re-absorption processes (Porcar Castell et al., 
2014). Sensitivity analyses of RTMs have provided general information on the impact of biochemical and structural effects on SIF (Koffi et al., 2015; Verrelst et al., 2016). Nonetheless, applying RTMs for interpreting field measurements of SIF remains challenging, because it requires canopy structure and leaf properties as inputs, which are generally not known a priori.

The use of reflectance spectra to parametrize an RTM for SIF is a promising strategy to resolve this problem. Studies have shown that several key leaf properties and canopy structure parameters can be retrieved from reflectance by inverting an RTM (Jacquemoud, 1993; Van der Tol et al., 2016; Verhoef et al., 2018). The retrieved parameters controlling the leaf and canopy radiative transfer may be used to estimate vegetation biochemical and structural effects on SIF. For example, Zhang et al. (2014) estimated leaf parameters (e.g., leaf water, chlorophyll and dry matter content) from satellite reflectance indices. The resulting parameters, together with estimates of leaf area index (LAI) and leaf angles, constrained the non-physiological factors in an RTM (i.e., the SCOPE model (Van der Tol et al., 2009)) and allowed the derivation of empirical relationships between seasonal photosynthetic capacity and TOC SIF.

The present study aims to assess the use of TOC reflectance and RTMs to infer vegetation biochemical and structural effects on TOC SIF. We used a unique airborne dataset comprising TOC reflectance and SIF taken before and during a heat event in 2015 with the HyPlant system (Rascher et al., 2015). The TOC reflectance was used to estimate canopy structure and leaf properties by inverting an RTM. The resulting vegetation parameters were further used to estimate vegetation biochemical and structural effects on SIF 
86

by using SCOPE.

\section{Study area and materials}

\subsection{Study area}

All analyses were performed in a 3 ha $(100 \mathrm{~m} \times 300 \mathrm{~m})$ experimental field (Fig. 1). The field is located in the agricultural experimental research station Campus Klein Altendorf of the University of Bonn, Germany (50³7' $\left.\mathrm{N}, 6^{\circ} 59^{\prime} \mathrm{E}\right)$. The average altitude of the field is $65 \mathrm{~m}$ above mean sea level. The mean annual precipitation is $603 \mathrm{~mm}$ and the mean annual temperature is $9.4^{\circ} \mathrm{C}$. There are two weather stations within the research station continuously recording meteorological data, such as air temperature and precipitation. The study area faced a heat event which started on July 1st and lasted to July 5 th in 2015 with maximum temperatures exceeding $30^{\circ} \mathrm{C}$ on each of these days (Dong et al., 2016).

At the study site, four crop types, notably corn (Zea mays L.), winter wheat (Triticum aestivum L.), winter barley (Hordeum vulgare L.) and rapeseed (Brassica napus L.), were grown using common field rotation practices. These four crops are the main crop types in western Germany. The soil and crops in the study area were treated according to the agricultural practices of the region with the aim to obtain spatially homogeneous crops. Corn, however, was planted with two different densities resulting one sparse and another dense canopy. To constrain airborne data processing, three (black, grey and white) reference panels were placed next to the experimental field. 


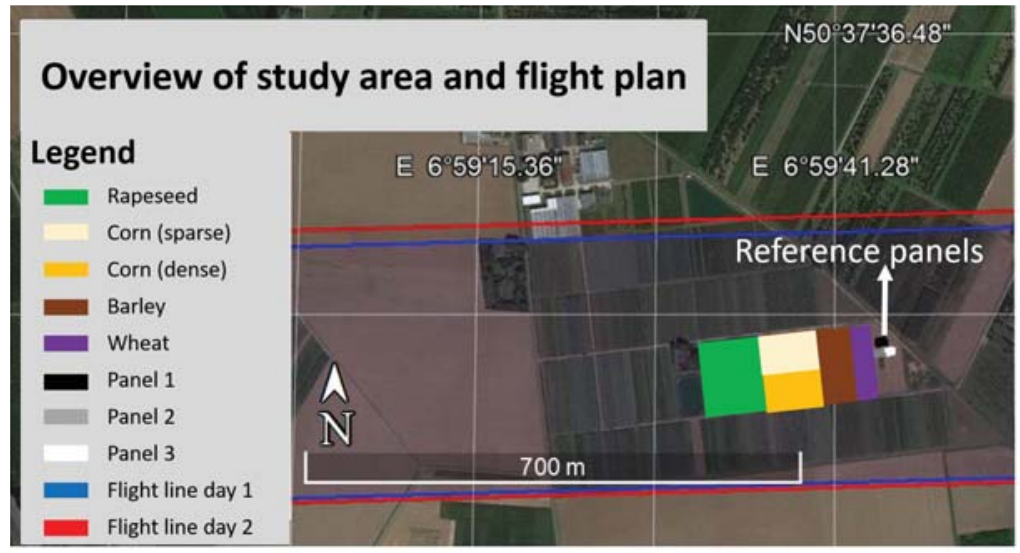

Figure 1: Overview of the study area and the flight plan before (June 30th, day 1) and during (July 2nd, day 2) the heat event. The crops investigated in the study and three reference panels are marked with polygons. The background image was acquired on 24th August 2016 (from Google Earth).

\subsection{Airborne experiment}

The airborne campaigns were conducted on June 30th (day 1, one day before the heat event) and on July 2nd (day 2, during the heat event). Both flights were carried out between 15:00 and 16:00 (local time, UTC+2) at an altitude of $512 \mathrm{~m}$ above sea level. Flights were carried out at similar solar zenith angles (i.e., $38^{\circ}$ and $34^{\circ}$ ) under clear sky conditions. At the time that the airborne data were collected, the incident photosynthetically active radiation (iPAR) was similar on the two days (i.e., $1278.8 \mu \mathrm{mol} \mathrm{m}^{-2} \mathrm{~s}^{-1}$ and $1366.2 \mu \mathrm{mol} \mathrm{m}{ }^{-2} \mathrm{~s}^{-1}$ ), while the air temperatures were markedly different (i.e. $26.6^{\circ} \mathrm{C}$ on day 1 and $33.7^{\circ} \mathrm{C}$ on day 2 ) due to the heat event.

To obtain the necessary data, a hyperspectral imaging spectrometer and a thermal camera were employed in the airborne campaigns. The hyperspectral spectrometer used in this study was HyPlant, which is a novel air- 
borne spectrometer dedicated to vegetation functional monitoring (Rascher et al., 2015). It consists of a dual-channel (DUAL) module and a fluorescence (FLUO) module. These two modules allow measuring red SIF at 687 $\mathrm{nm}\left(F_{687}\right)$ and far-red SIF at $760 \mathrm{~nm}\left(F_{760}\right)$, and reflectance from $400 \mathrm{~nm}$ to $2500 \mathrm{~nm}$. Specifically, the DUAL module measures contiguous spectra from 380 to $2500 \mathrm{~nm}$ with a spectral resolution of $3 \mathrm{~nm}$ in visible and near infrared region, and $10 \mathrm{~nm}$ in the short-wave infrared region. The FLUO module measures in 1024 contiguous spectral bands from 670 to $780 \mathrm{~nm}$, with a spectral resolution of $0.25 \mathrm{~nm}$. A set of representative measurements of the two modules is shown in Fig. S1 in the supplementary materials. The thermal camera used here was the VarioCAM (InfraTec, Germany). The thermal camera was connected to a laptop via GigaEthernet and processed with the IRBIS $₫ 3$ software (Infratec, Germany). The system allows real-time tracking of the measurements and correction of the absolute temperature by setting emissivity (i.e. 0.98 was assumed in this study), background temperature, ambient air temperature, air humidity and objects distance. Both the DUAL and FLUO module (i.e., two imagers), together with the thermal camera, were properly mounted on a single platform with the mechanical capability to align the field of view (FOV).

Supporting atmospherical parameters were acquired to support airborne data processing. They were measured with a sun photometer MICROTOPS II (Solar Light, the USA) at the same site every 5 minutes during the time of airborne flights. Additional meteorological parameters from the weather stations are listed in Table 1. 
Table 1: The meteorological conditions during the airborne campaigns before and during the heat event.

\begin{tabular}{lcc}
\hline Parameters & 30th June (Day 1) & 2nd July (Day 2) \\
\hline DOY (day of year) & 182 & 184 \\
Acquisition time (local) & $15: 51$ & $15: 16$ \\
Solar zenith $\left(\theta_{s}\right.$, degree) & 38 & 34 \\
Solar azimuth $\left(\psi_{s}\right.$, degree) & 237 & 224 \\
Air temperature $\left(T_{a},{ }^{\circ} \mathrm{C}\right)$ & 26.6 & 33.7 \\
Shortwave radiation $\left(\mathrm{W} \mathrm{m}^{-2}\right)$ & 756 & 808 \\
Wind speed $\left(\mathrm{m} \mathrm{s}^{-1}\right)$ & 3 & 2 \\
Air pressure $(\mathrm{hPa})$ & 997 & 996 \\
\hline
\end{tabular}

2.3. Measurements of reflectance, SIF and temperature

TOC reflectance was calculated from data measured by the DUAL module, and TOC SIF was calculated from data measured by the FLUO module. HyPlant data processing and TOC reflectance calculation have been described in detail by Rascher et al. (2015). Details of SIF retrieval can be found in Damm et al. (2014) and Wieneke et al. (2016). In the following, we outline the main procedure.

Data preprocessing included several steps: First, measured raw data (digital numbers) of both modules were converted to calibrated at-sensor radiance data using the radiometric calibration coefficients provided by the manufacturer. Second, resulting at-sensor radiance images were then geometrically rectified using navigation data recorded by the GPS/IMU unit and resized to a spatial grid of $0.5 \mathrm{~m} \times 1 \mathrm{~m}$. Afterwards, the geometrically rectified 
at-sensor radiance images from the DUAL module and the FLUO module were used differently to obtain TOC reflectance and TOC SIF, respectively.

To obtain TOC reflectance, the preprocessed DUAL images were atmospherically corrected using an atmospheric and topographic correction approach for flat terrain (ATCOR-4) (Richter and Schlapfer, 2012). ATCOR-4 is based upon the atmospheric radiative transfer code MODATRAN-5 (Berk et al., 2005) to pre-calculate look-up tables (LUT) of atmospheric functions such as transmission, spherical albedo and path scattered radiance. The atmosphere type and aerosol model were set to mid-latitude summer and a rural aerosol model. Solar position, ground elevation, and sensor elevation were parameterized exactly to the actual measurements during data acquisition. This parameterization was combined with estimates of atmospheric water vapor and aerosol optical thickness from MICROTOPS II to better account for atmospheric absorption and scattering effects.

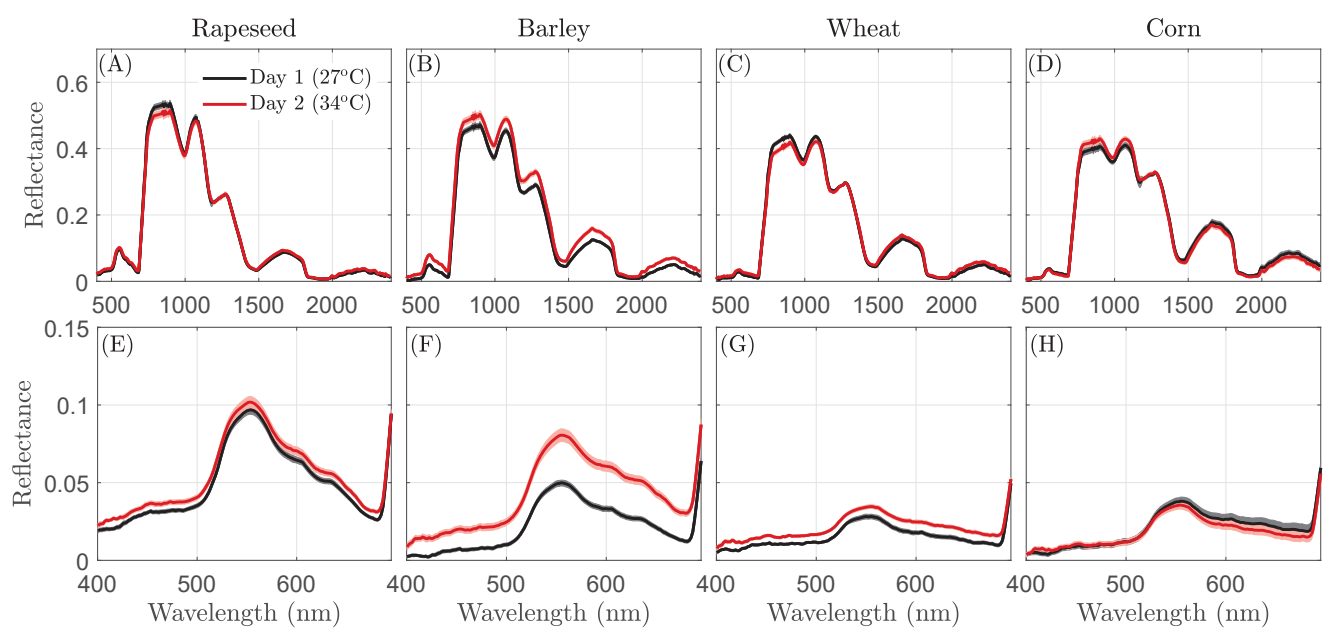

Figure 2: Reflectance measurements on day 1 and day 2 in the spectral region of $400-2500$ $\mathrm{nm}$ and $400-700 \mathrm{~nm}$. The buffers represent the standard deviation of the measurements. 
TOC SIF was retrieved from the preprocessed FLUO images by using an FLD-based approach. SIF in the two oxygen absorption bands (i.e., $\mathrm{O}_{2}$-A and $\mathrm{O}_{2}$-B) located at $687 \mathrm{~nm}\left(F_{687}\right)$ and $760 \mathrm{~nm}\left(F_{760}\right)$ was retrieved. The SIF retrieval was based on the iFLD method introduced by Alonso et al. (2008) as a modification of the original FLD method (Plascyk, 1975). We further updated the method to make it applicable to airborne use. The main update comprises the use of non-fluorescent reference surfaces (i.e., the reference panels) to correct potential inaccuracies in estimating atmospheric functions. Such errors can occur if atmospheric parameters are not exactly known or slight sensor artifacts remain (cf. Damm et al. (2014) and Wieneke et al. (2016) for details). The reliability of obtained SIF using this method was confirmed by validation activities considering ground fluorescence measurements (Rossini et al., 2015; Rascher et al., 2015).

The reflectance measurements and SIF at $687 \mathrm{~nm}$ and $760 \mathrm{~nm}$, together with the measurements of brightness temperature are shown in Fig. 2 and 3. Both reflectance, SIF and temperature varied among the four crops and between two days.

\subsection{The SCOPE model}

The SCOPE model (Van der Tol et al., 2009) was used to retrieve vegetation parameters from TOC reflectance and to estimate the biochemical and structural effects on TOC SIF. SCOPE consists of one leaf RTM (Vilfan et al., 2016), three canopy RTMs (Verhoef, 1984; Van der Tol et al., 2009), a biochemical model (Van der Tol et al., 2014), a soil reflectance model (Verhoef et al., 2018), an aerodynamic model and an energy balance model (Van der Tol et al., 2009). These models are internally connected. We briefly 
June $30,2015\left(27^{\circ} \mathrm{C}\right)$
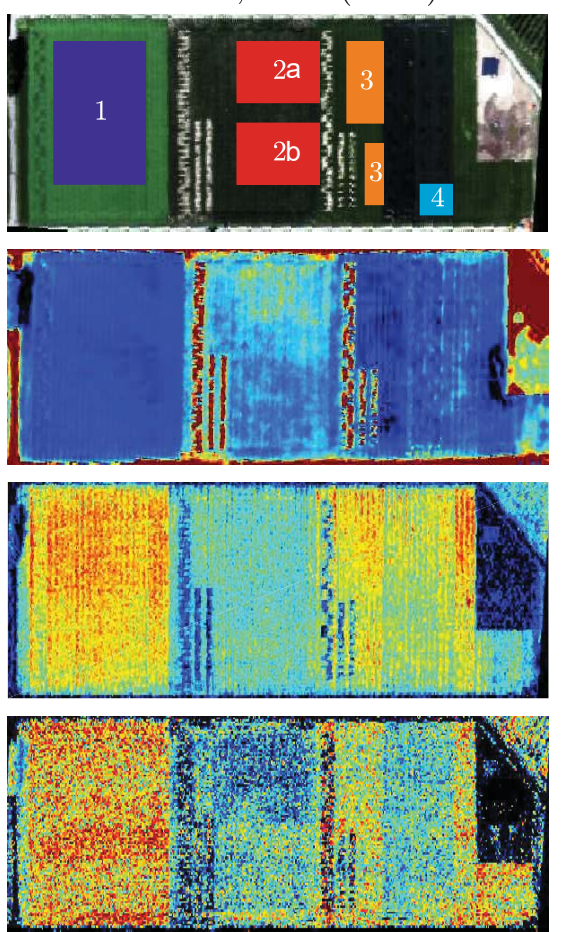

July $2,2015\left(34^{\circ} \mathrm{C}\right)$
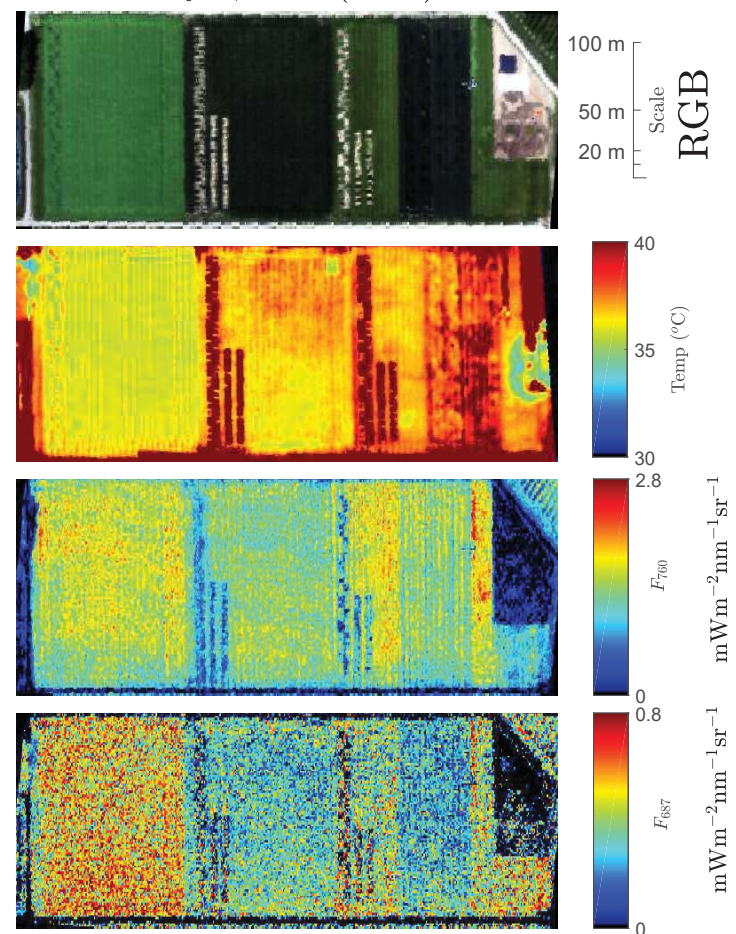

Figure 3: RGB, temperature, SIF at $687 \mathrm{~nm} F_{687}$ and at $760 \mathrm{~nm} F_{760}$ images of the experiment area before and during the heat event. Crops are marked in the RGB image: 1: rapeseed; 2a: corn (sparse); 2b corn (dense); 3: barley; 4: wheat.

introduce the models (combinedly) used in this study.

The Brightness-Shape-Moisture (BSM) model simulates soil reflectance. BSM separates the effects of soil brightness, soil moisture and spectral shape on soil reflectance and requires soil brightness $(B)$, soil moisture $\left(S M_{p}\right)$, and two spectral-shape related parameters $(\varphi$ and $\lambda$ ) (Table 2) (Verhoef et al., 2018). Fluspect (Vilfan et al., 2016), which is based on PROSPECT (Jacquemoud and Baret, 1990), simulates leaf reflectance, transmittance, and 
fluorescence emission of both forward (shaded) and backward (illuminated) side. Simulation of SIF emission of a leaf requires the input of incident radiation to the leaf and fluorescence emission efficiency $\left(\epsilon_{F}\right)$. The overall efficiency is estimated with the biochemical model of Van der Tol et al. (2014) and distributed over different wavelengths following Vilfan et al. (2016).

At the canopy level, RTMo, RTMf and RTMt, which are three SAIL (Verhoef, 1984) based models, compute the radiative transfer of incident radiation, emitted fluorescence and thermal radiation, respectively. RTMo provides TOC reflectance simulations, and $\mathrm{APAR}_{c h l}$ of each leaf in different positions in the canopy. RTMf simulates the radiative transfer of emitted SIF by leaves in a canopy and TOC SIF. SIF emission from each leaf can be simulated by Fluspect, using leaf $\mathrm{APAR}_{c h l}$ from RTMo and fluorescence emission efficiency from the biochemical model. RTMt calculates absorbed and emitted thermal radiation of each leaf. Simulation of the thermal radiation requires the temperatures of all leaves as input, on the other hand the temperatures in turn depend on the absorbed thermal radiation. Therefore it is necessary to iterate in order to obtain energy balance closure.

\section{Methods}

Our approach was to use reflectance to quantify soil, leaf and canopy properties, before using SCOPE to simulate vegetation biochemical and structural (i.e., non-physiological) effects on the measured SIF. As summarized in Fig. 4, we first retrieved vegetation parameters from TOC reflectance by inverting the reflectance routine of SCOPE (i.e., RTMo). Afterwards, we used the retrieved properties to simulate TOC SIF by using RTMf with a fixed 
Table 2: The ranges and initial values of the key parameters used in SCOPE .

\begin{tabular}{|c|c|c|c|c|}
\hline Parameter & Interpretation & Unit & Range & Initial value \\
\hline & \multicolumn{4}{|l|}{ Soil: BSM (Verhoef et al., 2018) } \\
\hline$B$ & Soil brightness & - & $0-0.9$ & 0.5 \\
\hline latitude $(\varphi)$ & Soil spectral latitude & - & $10-60$ & 45 \\
\hline longitude $(\lambda)$ & Soil spectral longitude & - & $10-50$ & 40 \\
\hline \multirow[t]{2}{*}{$S M_{p}$} & Soil moisture volume percentage & - & $5-55$ & 20 \\
\hline & \multicolumn{4}{|c|}{ Leaf model: Fluspect (Vilfan et al., 2016) } \\
\hline$C_{a b}$ & Chlorophyll $a+b$ content & $\mu \mathrm{g} \mathrm{cm}{ }^{-2}$ & $0-80$ & 40 \\
\hline$C_{d m}$ & Leaf mass per unit area & $\mathrm{g} \mathrm{cm}^{-2}$ & $0-0.02$ & 0.01 \\
\hline$C_{w}$ & Equivalent water thickness & $\mathrm{cm}$ & $0-0.1$ & 0.02 \\
\hline$C_{s}$ & Brown pigments & a.u. & $0-1$ & 0.5 \\
\hline$C_{c a}$ & Carotenoid content & $\mu \mathrm{g} \mathrm{cm}{ }^{-2}$ & $0-30$ & 10 \\
\hline \multirow[t]{2}{*}{$N$} & Leaf structure parameter & - & $0-3$ & 1.5 \\
\hline & \multicolumn{4}{|c|}{ Canopy models: RTMo and RTMf (Van der Tol et al., 2009) } \\
\hline LAI & Leaf area index & $\mathrm{m}^{2} \mathrm{~m}^{-2}$ & $0-7$ & 3 \\
\hline LIDFa & Leaf inclination determination a & - & $-1-1$ & -0.35 \\
\hline $\mathrm{LIDFb}$ & Leaf inclination determination $\mathrm{b}$ & - & $-1-1$ & -0.15 \\
\hline
\end{tabular}


fluorescence emission efficiency $\left(\epsilon_{F}\right)$. Finally, we inferred the impact of vegetation biochemistry and structure on the variation of SIF by comparing the measured SIF with modelled SIF. The approach was evaluated by an error propagation analysis. For further completely independent validation of the SCOPE forward modelling, we compared the measured brightness temperature to simulated brightness temperature.

\subsection{Retrieving soil, leaf and canopy parameters from reflectance}

\subsubsection{Characterizing soil background}

Soil background information of the canopies were partially obtained from bare soil pixels. We assumed that in the study area soil beneath the canopies differentiate from the bare soil only by moisture $\left(S M_{p}\right)$. In other words, the other three soil parameters, $B, \varphi$ and $\lambda$ were assumed to be the same for vegetation-covered soil and of bare soil. By assuming this, we retrieved $B$, $\varphi$ and $\lambda$ from the reflectance spectra of the bare soil, and used the retrieved parameters to characterize vegetation-covered soil. To obtain the values of these three parameters, twenty soil spectra were taken from the images on each day. For the retrieval of the parameters from each of these reflectance spectra, we used the numerical optimization method. The numerical optimization method aims at minimizing a cost function, which quantifies the differences between measured and simulated signals by successive changes of the input parameters. The cost function is

$$
f_{\text {soil }}=\left(R_{s}-R_{m}\right)^{T}\left(R_{s}-R_{m}\right)
$$

where $R_{s}$ is simulated (soil) reflectance, and $R_{m}$ is the measured (soil) reflectance in all bands of the spectra between 400 and $2500 \mathrm{~nm}$ (i.e., 623 




Figure 4: Flowchart of estimating the impact of vegetation biochemistry and structure effects on TOC SIF. Note: 'R', 'F', 'T' and 'P' refer to reflectance, fluorescence, temperature and vegetation parameters, respectively. '1' and '2' represent day 1 and day 2, respectively. RTMo, RTMf and RTMt are three submodels in SCOPE.

bands). The reflectance spectra of bare soil are shown in Fig. S2 in the supplementary materials. We used the function 'lsqnonlin' of the optimization toolbox of Matlab R2017a, selecting a Trust Region algorithm for updating parameter values within the ranges shown in Table 2. The BSM model was iteratively executed and iteration stopped when the improvement of the cost 
function $\left(f_{\text {soil }}\right)$ was less than $10^{-3}$.

\subsubsection{Retrieving leaf and canopy parameters}

We retrieved the leaf and canopy parameters on the two days independently from the TOC reflectance spectra of vegetation canopies. We again used the numerical optimization method and minimized the cost function (Eq. 1), but now using the reflectance of vegetation canopies and the canopy reflectance model (i.e., coupling RTMo and BSM) instead of the bare soil reflectance and BSM.

We selected several representative measurements from the reflectance and SIF images to perform the retrieval as the numerical optimization method is computationally demanding. The average of reflectance or SIF within a randomly selected patch consisting of 5 by 5 pixels was taken as one measurement of a crop. We sampled 16 patches for every crop except wheat, for which only eight patches were chosen due to the small size of the wheat field. Eight patches were sampled from each of the two corn fields. There were 112 patches (i.e., 56 for each day) selected in total.

Prior information is crucial to reduce the ill-posedness of the inverse problems. The soil parameters, $B, \varphi$ and $\lambda$, were kept to the average values retrieved from the reflectance of bare soil, while $S M_{p}$ of each canopy was treated as an unknown parameter and was estimated from TOC reflectance. In addition to the soil background, the observational conditions were predefined. The solar zenith angles were calculated according to the acquisition time and location as $38^{\circ}$ for day 1 and was $34^{\circ}$ for day 2 . We assumed the sensor view angle as spatially constant on a single image and in nadir direction although the HyPlant field of view ranged from $+/-14^{\circ}$. For a nadir 
view, the azimuth angle is arbitrary. Furthermore, the spectra of incoming direct solar light and diffuse light were directly obtained from MODTRAN 5 (Berk et al., 2005). With this prior information, fitting one reflectance spectrum eventually requires tuning 10 parameters, notably $S M_{p}, C_{a b}, C_{d m}$, $C_{w}, C_{c a}, N, \mathrm{LAI}, \mathrm{LIDFa}$ and LIDFb in Table. 2.

\subsection{Simulating TOC SIF and temperature}

We simulated the vegetation biochemistry and structure effects on TOC SIF by modelling SIF with RTMf. The retrieved soil, leaf and canopy parameters characterized the canopy, and the incident irradiance and sun-observer geometry defined the observational conditions. These factors controlled the light absorption and fluorescence re-absorption processes.

The other process, fluorescence emission, is parametrized by the fluorescence emission efficiency $\left(\epsilon_{F}\right)$, which describes the efficiency of the dissipation of APAR chl $_{\text {as }}$ fluorescence radiation. This efficiency, referred to as the 'physiological factor' in this study, is mainly determined by (1) $\mathrm{APAR}_{c h l}$, (2) leaf temperature, (3) the maximum rate of carboxylation $\left(V_{c \operatorname{cmax}}\right)$, and (4) other ambient environmental conditions, such as relative air humidity, air pressure and concentration of $\mathrm{O}_{2}$ and $\mathrm{CO}_{2}$ in the leaf boundary layer (Van der Tol et al., 2014).

To estimate the impact of the non-physiological factors, we treated the physiological status $\left(\epsilon_{F}\right)$ of the plants as a constant in all simulations. The value of $\epsilon_{F}$ was set to 0.014 (i.e. $40 \%$ above the default value of 0.01 in SCOPE for a dark adapted leaf), which is a realistic value for steady state fluorescence during daytime (Van der Tol et al., 2014). The spectral distribution of the efficiency followed Vilfan et al. (2016). We ran the whole SCOPE 
model to simulate TOC SIF (an output of RTMf) and canopy temperature (an output of RTMt and the energy balance model). We set the emissivity of leaves of all crops to 0.98. The brightness temperature from SCOPE was compared to the measurements for validation of the model inversion process.

\subsection{Error propagation analysis}

We analysed the propagation of noise in the measured reflectance spectra to the uncertainties (i.e., the standard deviations) in the retrieved parameters and further to the simulated TOC SIF. We used the spectrally averaged standard deviation of reflectance measurements of each reference panel (black, grey and white) (see Fig. S3 in the supplementary materials) as the noise of reflectance measurements $\left(\sigma_{R}=0.012\right)$. This uncertainty was comparable to the spectrally average change in reflectance of these panels between the two days, which was 0.014 . This approach provides a spectrally independent estimate of the reflectance uncertainty due to instrumental noise.

We first computed the Jacobians of SCOPE for TOC reflectance and SIF to simplify the local relationships among the measured reflectance, retrieved parameters and TOC SIF. The Jacobians $\left(\mathbf{J}_{R}\right.$ and $\left.\mathbf{J}_{F}\right)$ were computed for each set of optimized parameters and for each crop as:

$$
\mathbf{J}_{R}=\left[\begin{array}{ccc}
\partial R_{\lambda_{1}} / \partial p_{1} & \ldots & \partial R_{\lambda_{1}} / \partial p_{n} \\
\vdots \ldots & \ddots & \vdots \\
\partial R_{\lambda_{b}} / \partial p_{1} & \ldots & \partial R_{\lambda_{b}} / \partial p_{n}
\end{array}\right]
$$

$$
\mathbf{J}_{F}=\left[\begin{array}{ccc}
\partial F_{640} / \partial p_{1} & \ldots & \partial F_{640} / \partial p_{n} \\
\vdots \ldots & \ddots & \vdots \\
\partial F_{850} / \partial p_{1} & \ldots & \partial F_{850} / \partial p_{n}
\end{array}\right]
$$


where $\mathbf{J}_{R}$ is the local model sensitivity of reflectance at each wavelength of the $b$ bands of the HyPlant DUAL module $(b=623)$ to each of the 10 optimized parameters, and $\mathbf{J}_{F}$ is the local model sensitivity of TOC SIF spectra at each fluorescence wavelength (i.e., $640 \mathrm{~nm}-850 \mathrm{~nm}, 1 \mathrm{~nm}$ resolution) to each parameter. In total, we had 56 reflectance spectra on each day (i.e., 16 for rapeseed, barley and corn, and 8 for wheat), and thus 56 sets of optimized parameters and Jacobians. We analysed the Jacobians for measurements on day 1 only, because the Jacobians on day 2 were very similar to those on day 1.

Using the Jacobians the reflectance model is described with a locally linear approximation by $\Delta \mathbf{R}=\mathbf{J}_{R} \Delta \mathbf{p}$, where $\mathbf{p}$ is a matrix of the model parameters and $\mathbf{R}$ is reflectance spectra. The inverse model is given by

$$
\Delta \mathbf{p}=\left(\mathbf{J}_{R}^{\mathrm{T}} \mathbf{J}_{R}\right)^{-1} \mathbf{J}_{R}^{\mathrm{T}} \Delta \mathbf{R} .
$$

Therefore, the covariance matrix of $\mathbf{p}$ as a result of noise in reflectance can be obtained as:

$$
\begin{aligned}
E\left(\Delta \mathbf{p} \Delta \mathbf{p}^{\mathrm{T}}\right) & =E\left[\left(\mathbf{J}_{r}^{\mathrm{T}} \mathbf{J}_{R}\right)^{-1} \mathbf{J}_{R}^{\mathrm{T}} \Delta \mathbf{R} \Delta \mathbf{R}^{\mathrm{T}} \mathbf{J}_{R}\left(\mathbf{J}_{R}^{\mathrm{T}} \mathbf{J}_{R}\right)^{-1}\right] \\
& =\left(\mathbf{J}_{R}^{\mathrm{T}} \mathbf{J}_{R}\right)^{-1} \mathbf{J}_{R}^{\mathrm{T}} E\left(\Delta \mathbf{R} \Delta \mathbf{R}^{\mathrm{T}}\right) \mathbf{J}_{R}\left(\mathbf{J}_{R}^{\mathrm{T}} \mathbf{J}_{R}\right)^{-1}
\end{aligned}
$$

where $E\left(\Delta \mathbf{R} \Delta \mathbf{R}^{\mathrm{T}}\right)$ is the covariance matrix of the reflectance measurements. We assumed this covariance matrix is diagonal and uniform (all diagonal elements equal), characterized by a variance $\sigma_{R}^{2}$, and computed the covariance matrix of the retrieved parameters due to measurement noise as:

$$
E\left(\Delta \mathbf{p} \Delta \mathbf{p}^{\mathrm{T}}\right)=\left(\mathbf{J}_{R}^{\mathrm{T}} \mathbf{J}_{R}\right)^{-1} \sigma_{R}^{2}
$$

We further estimated the propagation of uncertainties in the retrieved parameters caused by noise in reflectance into the model simulation of TOC 
SIF.

$$
\begin{aligned}
E\left(\Delta \mathbf{F} \Delta \mathbf{F}^{\mathrm{T}}\right) & =E\left(\mathbf{J}_{F} \Delta \mathbf{p} \Delta \mathbf{p}^{\mathrm{T}} \mathbf{J}_{F}^{\mathrm{T}}\right)=\mathbf{J}_{F} E\left(\Delta \mathbf{p} \Delta \mathbf{p}^{\mathrm{T}}\right) \mathbf{J}_{F}^{\mathrm{T}} \\
& =\mathbf{J}_{F}\left(\mathbf{J}_{R}^{\mathrm{T}} \mathbf{J}_{R}\right)^{-1} \mathbf{J}_{F}^{\mathrm{T}} \sigma_{R}^{2}
\end{aligned}
$$

The standard deviation (uncertainty) of the simulated TOC SIF $\left(\sigma_{F}\right)$ was then found as the square roots of the diagonal elements of this matrix $\left(E\left(\Delta \mathbf{F} \Delta \mathbf{F}^{\mathrm{T}}\right)\right)$.

\section{Results}

\subsection{Results of retrieved vegetation parameters from TOC reflectance}

Table 3 lists the retrieved key parameter values. Among the four crops, there was considerable variation in the retrieved leaf chlorophyll and leaf water content. For example, the retrieved chlorophyll content of rapeseed was only half of that of corn, and the retrieved leaf water content of rapeseed was twice as high as that of corn. The retrieved canopy structure parameters LAI and average leaf angle (ALA), of which the latter one was calculated from LIDFa as $\mathrm{ALA}^{\circ}=45-360 \times \operatorname{LIDFa} \frac{1}{\pi^{2}}$ (Verhoef, 1998), varied moderately among the crops. LAI was clearly different for the two types of corn canopy, while, as expected, the other vegetation parameters showed no appreciable differences between the two corn fields. Besides the differences among the crops, the parameters retrieved from reflectance changed between the two days as well. For example, there were some changes in ALA and $C_{a b}$. In general, the model reproduced the measured TOC reflectance well with RMSE between 0.006 and 0.01 (for the comparison of the measured and modelled reflectance spectra, see Fig. S4 in the supplementary materials). 
Table 3: The retrieved values of soil moisture $\left(S M_{p}\right)$ leaf chlorophyll content $\left(C_{a b}\right)$, leaf water content $\left(C_{w}\right)$, canopy LAI and canopy average leaf angle (ALA) before and during the heat event. Note: the values are presented as 'mean (std)'.

\begin{tabular}{lcccccccccc}
\hline Parameter & \multicolumn{2}{c}{ Rapeseed } & \multicolumn{2}{c}{ Barley } & \multicolumn{2}{c}{ Wheat } & \multicolumn{2}{c}{ Corn (sparse) } & \multicolumn{2}{c}{ Corn (dense) } \\
& day 1 & day 2 & day 1 & day 2 & day 1 & day 2 & day 1 & day 2 & day 1 & day 2 \\
\hline$S M_{p}(\%)$ & $14.6(7.3)$ & $12.5(8.4)$ & $14.0(4.2)$ & $10.8(5.4)$ & $14.0(6.7)$ & $9.4(8.4)$ & $5.7(5.4)$ & $8.4(3.4)$ & $7.7(6.3)$ & $10.4(4.6)$ \\
$C_{a b}\left(\mu \mathrm{g} \mathrm{cm}^{-2}\right)$ & $22.9(0.3)$ & $21.7(1.6)$ & $32.6(2.3)$ & $27.4(3.0)$ & $50.2(1.8)$ & $49.4(2.6)$ & $39.1(1.3)$ & $45.5(2.0)$ & $42.8(1.0)$ & $51.5(1.8)$ \\
$C_{w}\left(\mathrm{~cm}^{-1}\right)$ & $0.07(0.001)$ & $0.065(0.003)$ & $0.04(0.002)$ & $0.036(0.002)$ & $0.038(0.002)$ & $0.036(0.0019)$ & $0.021(0.001)$ & $0.025(0.001)$ & $0.024(0.001)$ & $0.029(0.001)$ \\
LAI & $4.1(0.18)$ & $4.0(0.16)$ & $4.3(0.20)$ & $4.3(0.21)$ & $3.7(0.20)$ & $3.6(0.19)$ & $2.5(0.17)$ & $2.7(0.16)$ & $3.4(0.16)$ & $3.4(0.17)$ \\
ALA $\left(^{\circ}\right)$ & $51.6(4.6)$ & $58.0(3.2)$ & $64.8(2.6)$ & $67.0(2.8)$ & $66.3(1.6)$ & $69.1(2.1)$ & $71.6(1.7)$ & $67.4(2.2)$ & $70.0(1.8)$ & $64.7(2.2)$ \\
RMSE of refl & $0.01(0.007)$ & $0.01(0.007)$ & $0.008(0.005)$ & $0.006(0.007)$ & $0.007(0.004)$ & $0.006(0.007)$ & $0.007(0.003)$ & $0.006(0.003)$ & $0.007(0.003)$ & $0.006(0.004)$ \\
\hline
\end{tabular}

\subsection{Comparison between modelled and measured temperature}

Using the retrieved parameters in 4.1 as input, we modelled the brightness temperature with RTMt and the energy balance model in SCOPE. Fig. 5 shows a comparison between the measured and modelled brightness temperature. The simulated values were close to the measurements with $R^{2}=0.92$ and $\mathrm{RMSE}=0.76^{\circ} \mathrm{C}$. We also compared the modelled and measured differences between air temperature and canopy temperature $\left(T_{c}-T_{a}\right)$. The model predicted these differences well with $R^{2}=0.71$ and $\mathrm{RMSE}=0.7^{\circ} \mathrm{C}$.

\subsection{Simulation of biochemical and structural effects on SIF}

Fig. 6 shows the modelled and measured TOC SIF of the four crops. Although the physiological factors were assumed to be constant for four crops (i.e., $\epsilon_{F}=0.014$ ), the SIF variation among the four crops was reproduced well using the non-physiological information (i.e., the vegetation parameters retrieved in 4.1). Between the modelled and measured SIF, $R^{2}$ was 0.76 for $F_{687}$ and was 0.84 for $F_{760}$. The RMSE was 0.10 for $F_{687}$ and 0.12 $\mathrm{mWm}^{-2} \mathrm{~nm}^{-1} \mathrm{sr}^{-1}$ for $F_{760}$. In both modelled and measured SIF, there was a common tendency for $F_{687}$ and $F_{760}$ to be higher in rapeseed and barley than in wheat and corn. 

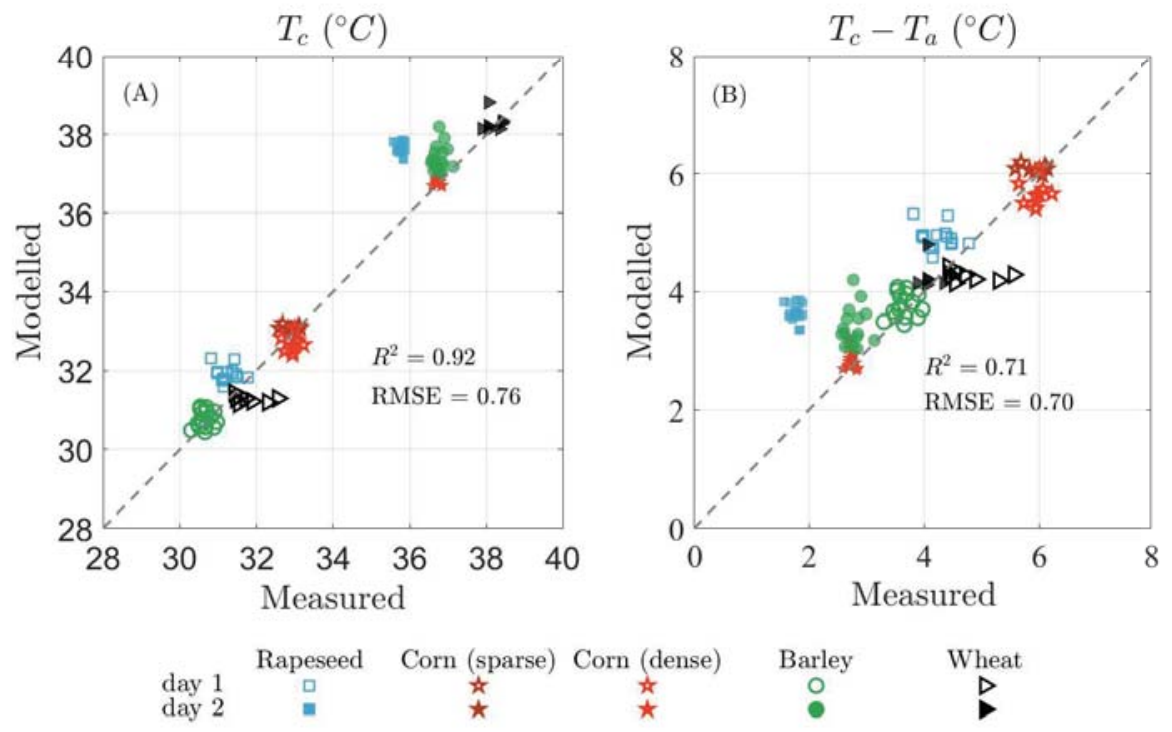

Figure 5: Modelled and measured canopy brightness temperature $\left(T_{c}\right)$ and canopy-air temperature differences $\left(T_{c}-T_{a}\right)$. 

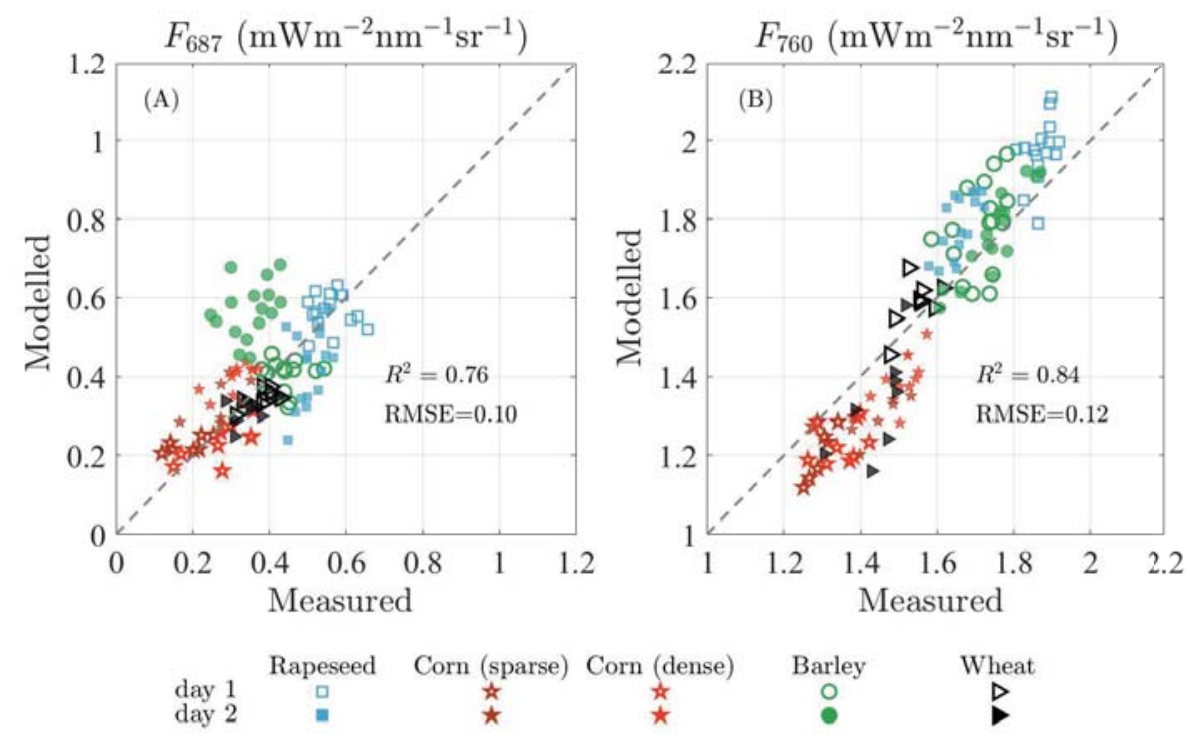

Figure 6: Modelled and measured red fluorescence $\left(F_{687}\right)$ and far-red fluorescence $\left(F_{760}\right)$.

Nevertheless there were some discrepancies between the measured and modelled SIF. In particular on day 2 , clear differences in $F_{687}$ between the simulations and measurements were found. The measured $F_{687}$ of barley on day 2 was much lower than the modelled values, while that of rapeseed was higher than the modelled values.

Fig. 7 shows SIF variation between the two days from the HyPlant measurements and from the model simulation. Although the fluorescence emission efficiency was set to the same on two days, the model simulation explained the changes in $F_{687}$ of wheat and in $F_{760}$ of rapeseed, corn and barley. Only for wheat a substantial discrepancy (over 60\%) between the model predicted and measured change in $F_{760}$ was found. The change in the measured $F_{760}$ was much better modelled than the change in $F_{687}$. For 
example, the measured $F_{687}$ of barley decreased on day 2 , but the modelled values increased. The simulated change in $F_{687}$ was higher than the measured change in both rapeseed and corn.
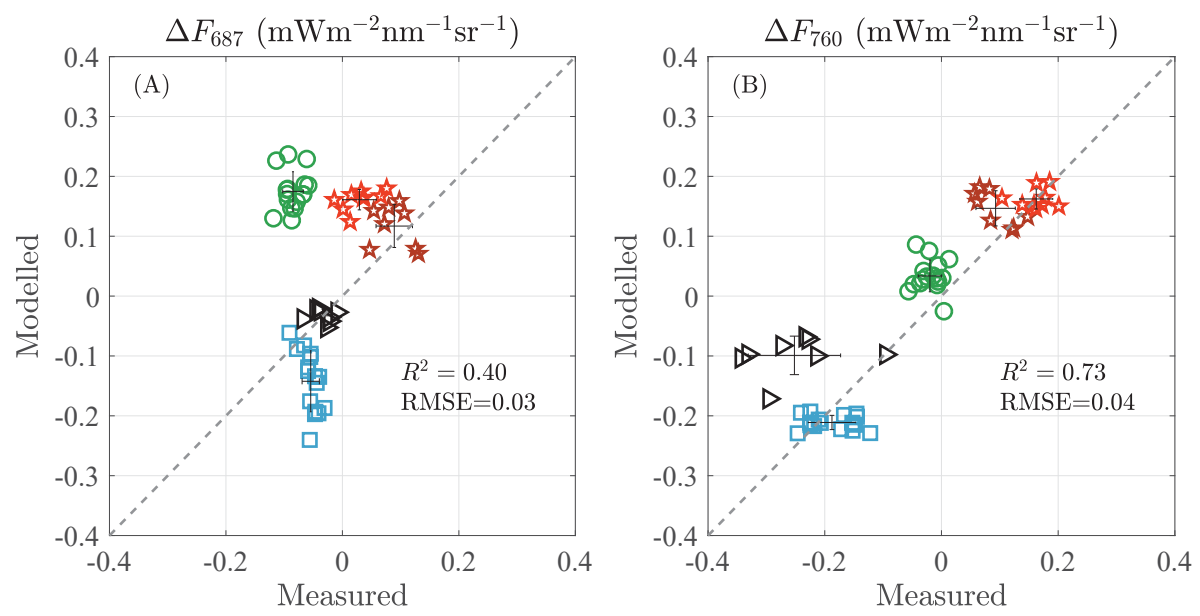

$\square$ Rapeseed $\star$ Corn (sparse) $\star$ Corn (dense) $\bigcirc$ Barley $\triangleright$ Wheat

Figure 7: Modelled and measured variation of SIF on two days (day 2 - day 1).

\subsection{Uncertainties from the error propagation analysis}

Table. 4 lists the uncertainties of the inferred parameters from the error propagation analysis. The average values and standard deviations of the 56 simulations on day 1 are presented. High uncertainties appeared in the retrieval of $S M_{p}$ and LIDFb. The uncertainties were $81 \%$ and $50 \%$ of their ranges in Table. 2, respectively. The inferred leaf structure parameter $N$ and ALA had moderate uncertainties. The remainder of the parameters had considerably lower uncertainty.

Fig. 8 shows the uncertainty of TOC SIF from the error propagation analysis. We took the values of 'measured SIF' of the reference panels (i.e., 
Table 4: The uncertainties of parameters estimated from the error propagation analysis. Note: the mean and standard derivation of the uncertainty in the 56 sets of retrieved parameters are presented, as well as the mean uncertainty relative to its range in Table. 2

\begin{tabular}{lccc}
\hline Parameter & mean uncertainty & std uncertainty & $\begin{array}{c}\text { mean uncertainty } \\
\text { (relative to its range) }\end{array}$ \\
\hline$S M_{p}[\%]$ & 40.5 & 29.4 & $81.0 \%$ \\
$C_{a b}\left[\mu \mathrm{g} \mathrm{cm}^{-2}\right]$ & 6.1 & 2.5 & $7.6 \%$ \\
$C_{d m}\left[\mathrm{~g} \mathrm{~cm}^{-2}\right]$ & 0.0085 & 0.001 & $40 \%$ \\
$C_{w}\left[\mathrm{~cm}^{-1}\right]$ & 0.0009 & 0.0001 & $0.9 \%$ \\
$C_{s}[-]$ & 0.030 & 0.005 & $3 \%$ \\
$C_{c a}\left[\mu \mathrm{g} \mathrm{cm}^{-2}\right]$ & 4.3 & 2.4 & $14.3 \%$ \\
$\mathrm{~N}[-]$ & 0.49 & 0.07 & $16.3 \%$ \\
$\mathrm{LAI}[-]$ & 0.7175 & 0.1 & $10.1 \%$ \\
$\mathrm{ALA}\left[{ }^{\circ}\right]$ & 24.7 & 6.8 & $27.4 \%$ \\
$\mathrm{LIDFb}[-]$ & 1.0 & $(0.4)$ & $50.0 \%$ \\
\hline
\end{tabular}

non-fluorescent targets) as the noise in the SIF measurements. The noise was 0.05 and $0.10 \mathrm{mWm}^{-2} \mathrm{~nm}^{-1} \mathrm{sr}^{-1}$ for $F_{687}$ and $F_{760}$ respectively. The uncertainties in the simulated SIF resulting from the measurement uncertainty in the reflectance were 0.00044 and $0.0037 \mathrm{mWm}^{-2} \mathrm{~nm}^{-1} \mathrm{sr}^{-1}$ at $687 \mathrm{~nm}$ and $760 \mathrm{~nm}$, respectively. These values were rather minor compared with the noise in the measured SIF.

\section{Discussion}

\subsection{Modelling biochemical and structural effects on SIF}

We simulated TOC SIF by using the vegetation parameters retrieved from TOC, while keeping the fluorescence emission efficiency $\left(\epsilon_{F}\right)$ constant. 


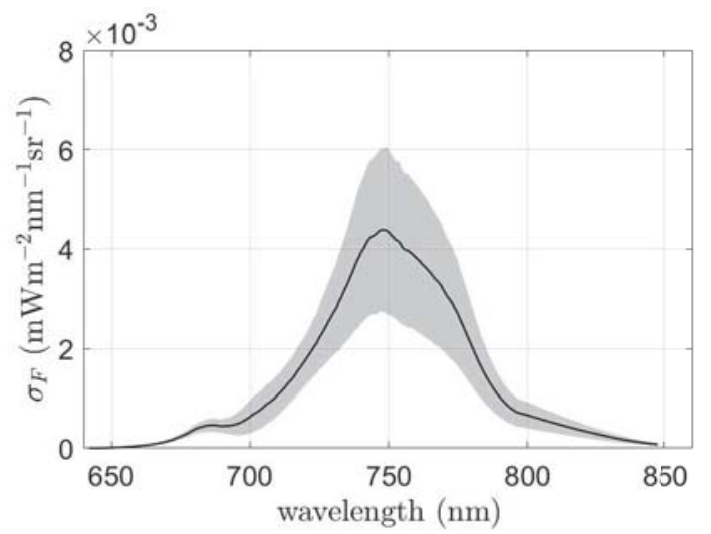

Figure 8: The uncertainty of TOC SIF simulation from error propagation analysis. The line and buffer represent the mean and standard deviation.

In this way, the simulated differences among crops and between the days in SIF were exclusively caused by differences in the absorption of PAR and the re-absorption of SIF, and they were fully independent of the fluorescence emission efficiency.

The variation in observed SIF among the crops and between the two days could be largely explained by the effects of different biochemical and structural properties. These effects explained $76 \%$ and $84 \%$ variation among the four crops for observed $F_{687}$ and $F_{760}$, respectively (Fig. 6). They also explained $40 \%$ and $73 \%$ variation between the two days for observed $F_{687}$ and $F_{760}$ (Fig. 7). These findings match with the results from a global sensitivity analysis conducted by Verrelst et al. (2015), which shows that over $80 \%$ of both red and far-red SIF variability is due to variation in biochemistry and structure.

The unexplained part of change in SIF may well be caused by changes in plant physiology, as represented in the model by the parameter $\epsilon_{F}$. On day 1 , 
the simulated SIF matched very well with the modelled SIF for all crops, but on day 2 there were clear differences between the modelled and simulated $F_{687}$ (Fig. 6A). By keeping the physiological factor constant, we overestimated $F_{687}$ in barley, but underestimated $F_{687}$ in rapeseed (Fig. $6 \mathrm{~A}$ ) and $F_{760}$ in corn (Fig. 6B). This would imply (assuming that our estimation of the structural effects on SIF was correct), that $\epsilon_{F}$ differed among the crops on day 2, and that $\epsilon_{F}$ changed between the two days. An estimate of the canopy effective $\epsilon_{F}$ can be obtained by normalizing measured by modelled SIF. The good match between the model simulations and measurements on day 1 for both red and far-red SIF implies that $\epsilon_{F}$ of the crops was all close to 0.014 and the spectrum of the efficiency was close to the one in Vilfan et al. (2016). On day 2, the overestimation and underestimation mentioned above suggest that $\epsilon_{F}$ of the crops diverged from this priori value of 0.014 . In addition, the over- and underestimation of red SIF were inconsistent with those for far-red SIF, which could be either to a model representation errors (i.e. the shape of the emission spectrum) or SIF retrieval errors. The surface temperature on the second measurement day was well above the optimum for crops of the C3 photosynthetic pathway, and was in the range where temperature effects on enzyme kinetics may affect the light saturated carboxylation rates and thus the dissipation of energy over three pathways. However, in view of the lack of ground truth data for the fluorescence emission efficiency in this study, we were unable to substantiate the hypothesis that the remaining variability of SIF is indeed due to the physiological regulation of the energy dissipation pathways. With our methodology we nevertheless demonstrate that there is remaining variability in SIF after correction for the dominant biochemical 
and structure effects.

Comparing SIF at $687 \mathrm{~nm}$ and $760 \mathrm{~nm}$, we found that the non-physiological factors explained the variation in $F_{760}$ much better that the variation in $F_{687}$ (Fig. 7). This indicates that $\epsilon_{F}$ at the two bands changed differently and the spectral shape of $\epsilon_{F}$ varied between the two days. The physiological variation caused more variation in $F_{687}$ than in $F_{760}$. This is consistent with the general understanding that physiological information is most profound in red SIF (Rossini et al., 2015; Verrelst et al., 2016). The different sensitivity of red and far-red SIF to the photosynthetic activity offers the approach of using red/far-red SIF ratio to better infer physiological status.

\subsection{Uncertainty and simulation accuracy}

Ill-posedness of retrievals is a common problem in model inversions. Parameters that have little influence on reflectance may not be accurately retrieved. The high uncertainties in the retrieved $S M_{p}$ and LIDFb (Table. 4) found in the error propagation analysis are directly related to their small contribution to TOC reflectance compared to for example LAI and LIDFa (Jacquemoud et al., 1995; Verrelst et al., 2015). As a consequence, soil information and LIDFb cannot be accurately retrieved from TOC reflectance. Fortunately, it appears that TOC SIF is not sensitive to these parameters either (Verrelst et al., 2016; Van der Tol et al., 2016). The uncertainties of these parameters will have little effect on uncertainties in the simulation of the vegetation biochemical and structural effects on SIF. In contrast, SIF is more sensitive to LAI and $C_{a b}$, of which the retrievals from reflectance are usually reliable (Weiss et al., 2004; Houborg et al., 2007; Darvishzadeh et al., 2008). Earlier findings by Van der Tol et al. (2016) and Verrelst et al. (2015) 
showed that for both reflectance and SIF the most influential parameters were $C_{a b}, C_{d m}$, LIDFa and LAI. The shared sensitivities of reflectance and SIF to most vegetation parameters lead to low error in simulated SIF $\left(\sigma_{F}\right)$ (Fig. 8).

The rationale for using reflectance to estimate biochemical and structural effects on SIF is a close relationship between reflectance and SIF. TOC SIF and reflectance are connected through their common dependence on radiative transfer processes. On the one hand, the scattering of SIF is directly linked with TOC reflectance (Yang and Van der Tol, 2018). Reflectance measurements can be used to estimate the scattering effects on observed SIF (Liu et al., 2018). On the other hand, PAR absorption can be estimated from TOC reflectance as well. For example, the reflectance indices NDVI and EVI appear to be good measures of fPAR (Bartlett et al., 1989; Myneni et al., 2002). The vegetation biochemistry and structure affect TOC SIF through the process of PAR absorption and SIF scattering, and both processes can be characterized by reflectance directly.

A more intuitive way of understanding the similarity of reflectance and fluorescence changes over the two days is by considering the absorption as the complementary part of the reflectance. The increase of visible reflectance in rapeseed, barley and wheat (Fig. 2) indicates that these crops absorbed less radiation on day 2. The reduction of absorption of incident light is one of the causes for the decrease of $F_{687}$ and $F_{760}$ of the three crops in Fig. 7.

Other studies have reported a correlation between SIF and reflectance as well. Konings et al. (2017) showed that NDVI and SIF of grassland were strongly correlated with $R^{2}=0.67$. Badgley et al. (2017) reported that there 
was a strong correlation between satellite measurements of near-infrared reflectance index and SIF. The direct connection between SIF and reflectance could explain the low uncertainty in modelled SIF $\left(\sigma_{F}\right)$, although there were high uncertainties in some retrieved parameters $\left(\sigma_{p}\right)$. What matters more is the sensitivity of TOC SIF to reflectance than the sensitivity of reflectance to the individual model parameters.

The changes in some retrieved parameters between the two days were not significant compared with the uncertainties from the error propagation analysis (Table. 3 and 4). This does not necessary mean that the model failed to predict the changes in SIF from reflectance. In the error propagation analysis, we assumed the noise in reflectance was spectrally independent. This assumption may lead to overestimation of uncertainties in the retrieved parameters. Moreover, some systematic errors in reflectance on the two days, which were not considered in the error propagation, may cancel out errors in the inferred parameters.

The changes in retrieved $C_{a b}$ between the two days comply with qualitative knowledge on the growth stage of the crops. Rapeseed, barley and wheat were in beginning of their senescent stages and they decreased in $C_{a b}$. Corn, in contrast, was in the the vegetative stage V9 (i.e. before tasseling) and showed an increase in $C_{a b}$ due to growing. Moreover, the difference in LAI between the two corn plots complied with the different planting densities. According to the inferred LIDF (i.e. leaf inclination distribution function) parameters, the LIDFs of the four crops were subjected to either the plagiophile (i.e. $\mathrm{ALA}=45^{\circ}$ ) or erectophile type (i.e. $\mathrm{ALA}=81^{\circ}$ ). The inferred LIDFs are consistent with the literature, e.g. De Wit (1965); Zou et al. 
(2014) and Fang (2015). In addition, the estimated $C_{a b}$ values are within range of published data, e.g. Daughtry et al. (2000) for corn and Hamblin et al. (2014) for wheat. However, the lack of in-situ measurements for direct validation is a limitation of our study.

As an additional validation of our results, we compared modelled to measured brightness temperature. The model predicted the brightness temperature well by using the retrieved parameters and measured meteorological data (Fig. 5A). More importantly, the differences between brightness and above-canopy air temperature were predicted well (Fig. 5B). This provides confidence in the accuracy of the model and the retrieved parameters. The air-canopy temperature differences are determined by the latent and sensible heat exchange, which are affected by both canopy structure and stomatal conductance. The model predicted the temperature less well on day 2 probably due to the model misrepresentation of temperature dependence of stomatal aperture (i.e. the Ball-Berry parameter) or temperature dependence of rate coefficients and/or $V_{\text {cmax }}$ in the photosynthesis model.

\subsection{Implications}

The combination of reflectance and SIF enables us to advance the analysis SIF observations. HyPlant is a unique airborne system that measures reflectance spectra and fluorescence simultaneously with a very high spatial resolution. Several satellite missions also provide opportunities to explore the applications on larger scales, such as TROPOMI and GOME-2 (Joiner et al., 2013; Guanter et al., 2015). The planned Fluorescence Explorer (FLEX) satellite will orbit in tandem with one of the Sentinel-3 (S3) satellites taking advantage of its optical and thermal sensors to provide an integrated pack- 
age of measurements (Drusch et al., 2017). Verhoef et al. (2018) showed with synthetic scenarios that it was promising to retrieve vegetation biochemical and structural parameters from FLEX/S3 multi-sensor data. Although we did not provide an explicit study on heat stress detection due to a lack of supporting in-situ measurements, the approach we proposed has the potential in retrieving plant physiological and structural response to stress.

\section{Conclusions}

The physiological, biochemical and structural factors jointly control TOC fluorescence. We show that hperspectral reflectance alone explains a large portion of the SIF variation across space and time. This is due to the information contained in TOC reflectance about leaf and canopy structure properties. RTMs are a useful tool to not only retrieve the leaf and canopy parameters from reflectance, but also to estimate their effects on TOC SIF. The estimation is reliable because SIF and reflectance are directly connected through vegetation biochemical and structural properties. In our view, hyperspectral reflectance combined with RTMs provide exciting opportunities for the quantitative use of SIF observations and a comprehensive set of information to assess physiological, biochemical, and structural variation.

Acknowledgements This work was supported by the China Scholarship Council (CSC) to P.Y. under Grant 201406040058, and by the Netherlands Organization for Scientific Research, grant ALWGO.2017.018. Part of this work (common experiment and part of airborne acquisition) was performed within the German-Plant-Phenotyping Network which is funded by the German Federal Ministry of Education and Research (project identification num- 
ber: 031A053). Airborne acquisition and data analysis were financed by the European Space Agency (ESA) in the frame of the HyFLEX campaign (ESA contract no. 4000107143/12/NL/FF/If CCN3) and the FLEX Bridge study (ESA Contract No. 4000112341/14/NL/FF/gp) and the by the SFB/TR 32 Patterns in Soil-Vegetation-Atmosphere Systems: Monitoring, Modelling, and Data Assimilationsubproject D2 (www.tr32.de), funded by the Deutsche Forschungsgemeinschaft (DFG). Additional financial support was provided by the Forschungszentrum Jülich GmbH supporting the development and operation of HyPlant. The authors thank Jing Liu and Anatoly Gitelson for providing valuable advice and assistance on the manuscript. The authors thank Patrick Rademske for acquiring the airborne data and for assistance with the data processing.

\section{References}

Ač, A., Malenovskỳ, Z., Olejníčková, J., Gallé, A., Rascher, U., Mohammed, G., 2015. Meta-analysis assessing potential of steady-state chlorophyll fluorescence for remote sensing detection of plant water, temperature and nitrogen stress. Remote Sensing of Environment 168, 420-436.

Alonso, L., Gomez-Chova, L., Vila-Frances, J., Amoros-Lopez, J., Guanter, L., Calpe, J., Moreno, J., 2008. Improved Fraunhofer Line Discrimination method for vegetation fluorescence quantification. IEEE Geoscience and Remote Sensing Letters 5 (4), 620-624.

Badgley, G., Field, C. B., Berry, J. A., 2017. Canopy near-infrared reflectance and terrestrial photosynthesis. Science advances 3 (3), e1602244. 
Baker, N. R., 2008. Chlorophyll fluorescence: a probe of photosynthesis in vivo. Annu. Rev. Plant Biol. 59, 89-113.

Bartlett, D. S., Whiting, G. J., Hartman, J. M., 1989. Use of vegetation indices to estimate indices to estimate intercepted solar radiation and net carbon dioxide exchange of a grass canopy. Remote Sensing of Environment $30(2), 115-128$.

Berk, A., Anderson, G. P., Acharya, P. K., Bernstein, L. S., Muratov, L., Lee, J., Fox, M., Adler Golden, S. M., Chetwynd, J. H., Hoke, M. L., et al., 2005. MODTRAN 5: a reformulated atmospheric band model with auxiliary species and practical multiple scattering options: update. En: Defense and Security. International Society for Optics and Photonics, pp. $662-667$.

Damm, A., Guanter, L., Laurent, V., Schaepman, M., Schickling, A., Rascher, U., 2014. FLD-based retrieval of sun-induced chlorophyll fluorescence from medium spectral resolution airborne spectroscopy data. Remote Sensing of Environment 147, 256-266.

Darvishzadeh, R., Skidmore, A., Schlerf, M., Atzberger, C., 2008. Inversion of a radiative transfer model for estimating vegetation LAI and chlorophyll in a heterogeneous grassland. Remote Sensing of Environment 112 (5), 2592-2604.

Daughtry, C., Walthall, C., Kim, M., De Colstoun, E. B., McMurtrey Iii, J., 2000. Estimating corn leaf chlorophyll concentration from leaf and canopy reflectance. Remote sensing of Environment 74 (2), 229-239. 
Daumard, F., Goulas, Y., Champagne, S., Fournier, A., Ounis, A., Olioso, A., Moya, I., 2012. Continuous monitoring of canopy level sun-induced chlorophyll fluorescence during the growth of a sorghum field. IEEE Transactions on Geoscience and Remote Sensing 50 (11), 4292-4300.

De Wit, C. T., 1965. Photosynthesis of leaf canopies. Tech. rep., Pudoc.

Dong, B., Sutton, R., Shaffrey, L., Wilcox, L., 2016. The 2015 European heat wave. Bulletin of the American Meteorological Society 97 (12), S57-S62.

Drusch, M., Moreno, J., Del Bello, U., Franco, R., Goulas, Y., Huth, A., Kraft, S., Middleton, E. M., Miglietta, F., Mohammed, G., et al., 2017. The FLuorescence EXplorer Mission Concept-ESA's Earth Explorer 8. IEEE Transactions on Geoscience and Remote Sensing 55 (3), 1273-1284.

Fang, F., 2015. The retrieval of leaf inclination angle and leaf area index in maize. University of Twente, Masters Thesis.

Grace, J., Nichol, C., Disney, M., Lewis, P., Quaife, T., Bowyer, P., 2007. Can we measure terrestrial photosynthesis from space directly, using spectral reflectance and fluorescence? Global Change Biology 13 (7), 1484-1497.

Guanter, L., Aben, I., Tol, P., Krijger, J., Hollstein, A., Köhler, P., Damm, A., Joiner, J., Frankenberg, C., Landgraf, J., 2015. Potential of the TROPOspheric Monitoring Instrument (TROPOMI) onboard the Sentinel-5 Precursor for the monitoring of terrestrial chlorophyll fluorescence. Atmospheric Measurement Techniques 8 (3), 1337-1352.

Guanter, L., Zhang, Y., Jung, M., Joiner, J., Voigt, M., Berry, J. A., Frankenberg, C., Huete, A. R., Zarco Tejada, P., Lee, J.-E., et al., 2014. Global and 
time-resolved monitoring of crop photosynthesis with chlorophyll fluorescence. Proceedings of the National Academy of Sciences 111 (14), E1327E1333.

Hamblin, J., Stefanova, K., Angessa, T. T., 2014. Variation in chlorophyll content per unit leaf area in spring wheat and implications for selection in segregating material. PLoS One 9 (3), e92529.

He, L., Chen, J. M., Liu, J., Mo, G., Joiner, J., 2017. Angular normalization of GOME-2 sun-induced chlorophyll fluorescence observation as a better proxy of vegetation productivity. Geophysical Research Letters 44 (11), $5691-5699$.

Houborg, R., Soegaard, H., Boegh, E., 2007. Combining vegetation index and model inversion methods for the extraction of key vegetation biophysical parameters using Terra and Aqua MODIS reflectance data. Remote Sensing of Environment 106 (1), 39-58.

Jacquemoud, S., 1993. Inversion of the PROSPECT + SAIL canopy reflectance model from AVIRIS equivalent spectra: theoretical study. Remote Sensing of Environment 44 (2-3), 281-292.

Jacquemoud, S., Baret, F., 1990. PROSPECT: A model of leaf optical properties spectra. Remote Sensing of Environment 34 (2), 75-91.

Jacquemoud, S., Baret, F., Andrieu, B., Danson, F., Jaggard, K., 1995. Extraction of vegetation biophysical parameters by inversion of the PROSPECT + SAIL models on sugar beet canopy reflectance data. Appli- 
cation to TM and AVIRIS sensors. Remote Sensing of Environment 52 (3), $163-172$.

Joiner, J., Guanter, L., Lindstrot, R., Voigt, M., Vasilkov, A., Middleton, E., Huemmrich, K., Yoshida, Y., Frankenberg, C., 2013. Global monitoring of terrestrial chlorophyll fluorescence from moderate-spectral-resolution nearinfrared satellite measurements: methodology, simulations, and application to GOME-2. Atmospheric Measurement Techniques 6 (10), 2803-2823.

Koffi, E., Rayner, P., Norton, A., Frankenberg, C., Scholze, M., 2015. Investigating the usefulness of satellite-derived fluorescence data in inferring gross primary productivity within the carbon cycle data assimilation system. Biogeosciences 12 (13), 4067-4084.

Köhler, P., Guanter, L., Kobayashi, H., Walther, S., Yang, W., 2018. Assessing the potential of sun-induced fluorescence and the canopy scattering coefficient to track large-scale vegetation dynamics in Amazon forests. Remote Sensing of Environment 204, 769 - 785.

Konings, A., Williams, A., Gentine, P., 2017. Sensitivity of grassland productivity to aridity controlled by stomatal and xylem regulation. Nature Geoscience 10 (4), 284.

Liu, L., Liu, X., Wang, Z., Zhang, B., 2016. Measurement and analysis of bidirectional SIF emissions in wheat canopies. IEEE Transactions on Geoscience and Remote Sensing 54 (5), 2640-2651.

Liu, X., Guanter, L., Liu, L., Damm, A., Malenovskỳ, Z., Rascher, U., Peng, D., Du, S., Gastellu-Etchegorry, J.-P., 2018. Downscaling of solar-induced 
chlorophyll fluorescence from canopy level to photosystem level using a random forest model. Remote Sensing of Environment.

Maxwell, K., Johnson, G. N., 2000. Chlorophyll fluorescencea practical guide. Journal of experimental botany 51 (345), 659-668.

Miao, G., Guan, K., Yang, X., Bernacchi, C. J., Berry, J. A., DeLucia, E. H., Wu, J., Moore, C. E., Meacham, K., Cai, Y., et al., 2018. Suninduced chlorophyll fluorescence, photosynthesis, and light use efficiency of a soybean field from seasonally continuous measurements. Journal of Geophysical Research: Biogeosciences 123 (2), 610-623.

Migliavacca, M., Perez-Priego, O., Rossini, M., El-Madany, T. S., Moreno, G., van der Tol, C., Rascher, U., Berninger, A., Bessenbacher, V., Burkart, A., et al., 2017. Plant functional traits and canopy structure control the relationship between photosynthetic CO2 uptake and far-red sun-induced fluorescence in a Mediterranean grassland under different nutrient availability. New Phytologist 214 (3), 1078-1091.

Myneni, R. B., Hoffman, S., Knyazikhin, Y., Privette, J., Glassy, J., Tian, Y., Wang, Y., Song, X., Zhang, Y., Smith, G., et al., 2002. Global products of vegetation leaf area and fraction absorbed PAR from year one of MODIS data. Remote sensing of environment 83 (1-2), 214-231.

Plascyk, J. A., 1975. The MK II Fraunhofer line discriminator (FLD-II) for airborne and orbital remote sensing of solar-stimulated luminescence. Optical Engineering 14 (4), 144339. 
Porcar Castell, A., Tyystjärvi, E., Atherton, J., Van der Tol, C., Flexas, J., Pfündel, E. E., Moreno, J., Frankenberg, C., Berry, J. A., 2014. Linking chlorophyll a fluorescence to photosynthesis for remote sensing applications: mechanisms and challenges. Journal of Experimental Botany, eru191.

Rascher, U., Alonso, L., Burkart, A., Cilia, C., Cogliati, S., Colombo, R., Damm, A., Drusch, M., Guanter, L., Hanus, J., et al., 2015. Sun-induced fluorescence-a new probe of photosynthesis: First maps from the imaging spectrometer HyPlant. Global Change Biology 21 (12), 4673-4684.

Richter, R., Schlapfer, D., 2012. Atmospheric/topographic correction for airborne imagery: Atcor-4 user guide. DLR IB, 565-02.

Rossini, M., Nedbal, L., Guanter, L., Ač, A., Alonso, L., Burkart, A., Cogliati, S., Colombo, R., Damm, A., Drusch, M., et al., 2015. Red and far red sun-induced chlorophyll fluorescence as a measure of plant photosynthesis. Geophysical Research Letters 42 (6), 1632-1639.

Sun, Y., Frankenberg, C., Wood, J. D., Schimel, D., Jung, M., Guanter, L., Drewry, D., Verma, M., Porcar-Castell, A., Griffis, T. J., et al., 2017. OCO-2 advances photosynthesis observation from space via solar-induced chlorophyll fluorescence. Science 358 (6360), eaam5747.

Van der Tol, C., Berry, J., Campbell, P., Rascher, U., 2014. Models of fluorescence and photosynthesis for interpreting measurements of solar-induced chlorophyll fluorescence. Journal of Geophysical Research: Biogeosciences 119 (12), 2312-2327. 
Van der Tol, C., Rossini, M., Cogliati, S., Verhoef, W., Colombo, R., Rascher, U., Mohammed, G., 2016. A model and measurement comparison of diurnal cycles of sun-induced chlorophyll fluorescence of crops. Remote Sensing of Environment 186, 663-677.

Van der Tol, C., Verhoef, W., Timmermans, J., Verhoef, A., Su, Z., 2009. An integrated model of soil-canopy spectral radiances, photosynthesis, fluorescence, temperature and energy balance. Biogeosciences 6 (12), 3109-3129.

Verhoef, W., 1984. Light scattering by leaf layers with application to canopy reflectance modeling: the SAIL model. Remote Sensing of Environment $16(2), 125-141$.

Verhoef, W., 1998. Theory of radiative transfer models applied in optical remote sensing of vegetation canopies. Wageningen: Landbouwuniversiteit Wageningen (LUW).

Verhoef, W., van der Tol, C., Middleton, E. M., 2018. Hyperspectral radiative transfer modeling to explore the combined retrieval of biophysical parameters and canopy fluorescence from FLEX-Sentinel-3 tandem mission multi-sensor data. Remote Sensing of Environment 204, 942-963.

Verrelst, J., Rivera, J. P., van der Tol, C., Magnani, F., Mohammed, G., Moreno, J., 2015. Global sensitivity analysis of the SCOPE model: What drives simulated canopy-leaving sun-induced fluorescence? Remote Sensing of Environment 166, 8-21.

Verrelst, J., Van der Tol, C., Magnani, F., Sabater, N., Rivera, J. P., Mohammed, G., Moreno, J., 2016. Evaluating the predictive power of sun- 
induced chlorophyll fluorescence to estimate net photosynthesis of vegetation canopies: A SCOPE modeling study. Remote Sensing of Environment $176,139-151$.

Vilfan, N., van der Tol, C., Muller, O., Rascher, U., Verhoef, W., 2016. Fluspect-B: A model for leaf fluorescence, reflectance and transmittance spectra. Remote Sensing of Environment 186, 596-615.

Weiss, M., Baret, F., Smith, G., Jonckheere, I., Coppin, P., 2004. Review of methods for in situ leaf area index (LAI) determination: Part II. Estimation of LAI, errors and sampling. Agricultural and forest meteorology $121(1-2), 37-53$.

Wieneke, S., Ahrends, H., Damm, A., Pinto, F., Stadler, A., Rossini, M., Rascher, U., 2016. Airborne based spectroscopy of red and far-red suninduced chlorophyll fluorescence: Implications for improved estimates of gross primary productivity. Remote Sensing of Environment 184, 654-667.

Yang, K., Ryu, Y., Dechant, B., Berry, J. A., Hwang, Y., Jiang, C., Kang, M., Kim, J., Kimm, H., Kornfeld, A., et al., 2018. Sun-induced chlorophyll fluorescence is more strongly related to absorbed light than to photosynthesis at half-hourly resolution in a rice paddy. Remote Sensing of Environment $216,658-673$.

Yang, P., Van der Tol, C., 2018. Linking canopy scattering of far-red suninduced chlorophyll fluorescence with reflectance. Remote Sensing of Environment 209, 456-467. 
Yang, X., Tang, J., Mustard, J. F., Lee, J.-E., Rossini, M., Joiner, J., Munger, J. W., Kornfeld, A., Richardson, A. D., 2015. Solar-induced chlorophyll fluorescence that correlates with canopy photosynthesis on diurnal and seasonal scales in a temperate deciduous forest. Geophysical Research Letters $42(8), 2977-2987$.

Zhang, Y., Guanter, L., Berry, J. A., Joiner, J., Tol, C., Huete, A., Gitelson, A., Voigt, M., Köhler, P., 2014. Estimation of vegetation photosynthetic capacity from space-based measurements of chlorophyll fluorescence for terrestrial biosphere models. Global Change Biology 20 (12), 3727-3742.

Zhang, Y., Xiao, X., Wolf, S., Wu, J., Wu, X., Gioli, B., Wohlfahrt, G., Cescatti, A., van der Tol, C., Zhou, S., et al., 2018. Spatio-temporal convergence of maximum daily light-use efficiency based on radiation absorption by canopy chlorophyll. Geophysical Research Letters 45 (8), 3508-3519.

Zou, X., Mõttus, M., Tammeorg, P., Torres, C. L., Takala, T., Pisek, J., Mäkelä, P., Stoddard, F., Pellikka, P., 2014. Photographic measurement of leaf angles in field crops. Agricultural and forest meteorology 184, 137146. 